\title{
Gestão Escolar e (re)construção coletiva de Projetos Político-Pedagógicos nas Escolas do Campo: diálogos problematizadores e auto[trans]formativos
}

\section{School Management and collective (re)construction of Political Pedagogical Projects in Country Schools: Probleming and auto[trans]formative dialogues}

\author{
Elizandra Aparecida Nascimento Gelocha ${ }^{1 *}$, Helenise Sangoi Antunes ${ }^{1}$, Débora Ortiz de Leão ${ }^{1}$
}

\begin{abstract}
RESUMO
As discussões presentes neste texto decorrem de uma pesquisa de doutorado em Educação ${ }^{2}$ do Programa de Pós-Graduação em Educação da Universidade Federal de Santa Maria. As reflexões aqui apresentadas tiveram como objetivo sensibilizar e estimular docentes a participarem da construção de um Projeto Político-pedagógico (PPP) colaborativo, que colocasse em evidência os professores rurais enquanto educadores-políticos, capazes de tratar a educação para além da sala de aula, como cidadãos portadores de direitos civis e políticos, conscientes e autônomos, que refletem sua realidade política e pedagógica. Partimos de uma abordagem qualitativa e, nesse contexto, foram realizados Círculos Dialógicos Investigativo-formativos como proposta epistemológicopolítica que possibilita dialogar com os professores levando em conta a realidade, seus saberes, suas inquietações, curiosidades e questionamentos. O diálogo-problematizador proposto com relação a (re)construção coletiva dos PPPs foi importante para a compreensão das orientações apresentadas nos documentos oficiais como Base Nacional Comum Curricular (BNCC) e Referencial Curricular Gaúcho (RCG) e suas influências no processo educacional, além de ter proporcionado espaço de reflexão para entendermos que a implementação dos mesmos são oportunidades de revisar o currículo e adotar estratégias diferenciadas.
\end{abstract}

Palavras-chave: Projeto Político-pedagógico; Formação Permanente de Professores; Políticas públicas educacionais.

\begin{abstract}
The debates featured in this abstract steam from doctoral research in Education of the Graduate Program in Education at the Universidade Federal de Santa Maria. The remarks here presented had the purpose to sensibilize and stimulate professors towards to participate in the construction of a collaborative PoliticalPedagogical Project (PPP), which would emphasize rural teachers as political-educators, capable of providing education way beyond the walls of a classroom, as conscious and independent citizens with civil and political
\end{abstract}

${ }^{1}$ Universidade Federal de Santa Maria, Brasil.

* E-mail: elizandraang@gmail.com 
rights, who reflect their own political and pedagogical reality. We start from a qualitative approach. In the methodological context, Investigative-Formative Dialogic Circles were conducted as an epistemologicalpolitical proposal that makes it possible to speak with teachers considering their reality, knowledge, concerns, curiosities and doubts. The problematic dialogue proposed in this abstract, related to the collective (re)construction of PPPs had great importance for the comprehension of the guidelines presented in official documents such as the Base Nacional Comum Curricular (BNCC) and the Referencial Curricular Gaúcho (RCG) evidencing their impact on the educational process. Furthermore, the analysis of the problematic provided a space for reflection to understand that the implementation of transformative dialogues are opportunities to review the résumé and go for different strategies.

Keywords: Political Pedagogical Projects; Permanent teacher training; Educational Public Policies.

\section{INTRODUÇÃO}

O tema em destaque, surgiu de reflexões de formações permanentes que vinhamos desenvolvendo com professores gestores no contexto de Escolas do Campo de uma rede municipal do estado do Rio Grande do Sul. No decorrer da formação, ficou explícito que a realidade vivenciada pelos professores vinha sendo modificada pela prática social e que as interlocutoras (diretoras e supervisoras) estavam criando estratégias para suprir as necessidades das escolas. Também foi enfatizado que as escolas estavam em fase de construção do Projeto Político-pedagógico (PPP), pois antes tinham um PPP único para todas as escolas da rede, mas, devido à diversidade destas e, por exigência das leis, consideraram importante que cada instituição tivesse o seu documento.

Sabemos que a obrigatoriedade de as escolas possuírem seus PPPs foi definida pela Lei de Diretrizes e Bases, Lei no 9.394, de 20 de dezembro de 1996, que discute a necessidade de estabelecer uma gestão democrática, que garanta a comunidade escolar a possibilidade de contribuir no processo educacional (BRASIL, 1996a). Silva e Leão (2018, p. 79) enfatizam que "a gestão democrática se refere à partilha de responsabilidades, conhecimentos e tomada de decisão, entre outros, para que haja um bom andamento escolar”. Atualmente, no estado do Rio Grande do Sul, a construção ou revisão dos PPPs precisa se adequar ao Referencial Curricular Gaúcho (RCG), Resolução CEEd nº 345, de 12 de dezembro de 2018, que institui e orienta o currículo escolar (BRASIL, 2018).

As informações que surgiram no diálogo ressaltam que a gestão nas escolas devem dar vez e voz a seus atores, mediante a "construção do entendimento de responsabilidade coletiva pela educação" (LÜCK, 2011, p.81). A importância de envolver todos no processo 
de construção e implementação do PPP nos levou a dialogamos sobre o PPP, a Base Nacional Comum Curricular (BNCC) e a construção do Referencial Curricular Gaúcho (RCG). Sendo assim, é necessário pensar propostas de formação que levem em conta as diversidades culturais, sociais e regionais do país e oportunizem espaços de reflexão das ações pedagógicas histórico-críticas e emancipatórias.

\section{METODOLOGIA}

A abordagem metodológica deste estudo é configurada como pesquisa qualitativa, pois abriu espaços para uma investigação flexível, a qual, no caso, teve o intuito de nos aproximar cada vez mais das singularidades e das vivências partilhadas, a fim de compreender e analisar o contexto em que a pesquisa foi desenvolvida. As problematizações sobre gestão escolar tiveram como foco o percurso trilhado pelas interlocutoras (professoras gestoras), que têm a responsabilidade social de auxiliar na construção de propostas politicas e pedagógicas que norteiam as práticas na escola, sejam pedagógicas ou administrativas.

No contexto metodológico, utilizamos os Círculos Dialógicos Investigativoformativos, proposta epistemológico-política desenvolvida pelo Grupo de Pesquisa Dialogus: Educação, Formação e Humanização com Paulo Freire, que foi inspirada nos Círculos de Cultura preconizados por Paulo Freire (1979; 2011), com aportes teóricos da pesquisa-formação, de Marie-Christine Josso (2010) (TONIOLO; HENZ 2017). Essa proposta epistemológico-política permite dialogar com os professores levando em conta sua realidade, seus saberes, suas inquietações, curiosidades e questionamentos.

Essa metodologia qualitativa busca captar, entre as interlocutoras, percepções, sentimentos e ideias, fazendo emergir uma multiplicidade de pontos de vista e processos emocionais, decorrentes do próprio contexto de interação criado. Os mesmos autores ressaltam que a proposta adotada nos Círculos Dialógicos segue uma perspectiva freireana, na qual os saberes dos sujeitos envolvidos "se entrelaçam no grupo e, juntos, a partir do diálogo-problematizador, cooperativamente, vão desvelando a realidade com consciência crítica e transformadora" (TONIOLO; HENZ , 2017, p. 2).

Para registrar as narrativas das interlocutoras e preservar suas identidades, foram escolhidos pseudônimos a partir de um desafio, onde as professoras foram provocadas a escreverem uma palavra que representasse o significado de ser docente/gestora em Escolas 
do Campo. As palavras reproduzidas foram utilizadas para a identificação das interlocutoras, que foram simbolizadas por: Alegria, Luz, Esperança, Amor.

A proposta descrita possibilitou uma formação permanente de professores integrada e colaborativa, pautada nas experiências que as docentes percorrem na formação, sobretudo, na auto[trans]formação permanente. Nesse contexto, Freire (2001) afirma que a educação permanente é fundada na dialeticidade entre a prática e a teoria. Ainda na obra "Política e educação", Freire (2001) destaca que a formação permanente parte da noção do inacabamento, movimento que exige responsabilidade ética, política e profissional do educador ao se colocar na condição de sujeito inacabado.

Esse contexto metodológico de pesquisa qualitativa possibilitou produzirmos conhecimentos com rigor científico para fomentar a prática social transformadora, ou seja, a práxis, com o propósito de contribuir com a compreensão crítica e coletiva dos vieses ideológicos das propostas educativas, democráticas e humanizadoras. Os conhecimentos produzidos no estudo defendem uma Educação que coloque em evidência os professores enquanto educadores-políticos, capazes de tratar a educação para além da sala de aula, como cidadãos conscientes e autônomos, que reflitam política e pedagogicamente sobre sua realidade.

\section{RESULTADOS E DISCUSSÕES}

Se perguntarmos a uma criança pequena o que ela acha que quer dizer a palavra "gestão", provavelmente ela nos dirá que gestão quer dizer "gesto grande". E provavelmente os adultos que escutarem isso vão rir dela. Mas pensando bem, a gestão tem a ver exatamente com isso: com os gestos grandes que somos capazes de fazer. (KRAMER; NUNES, 2007, p. 452).

O excerto acima ressalta a importância da gestão na escola e vem ao encontro dos diálogos registrados na pesquisa, que teve como foco o percurso trilhado pelas interlocutoras (professoras gestoras), que têm a responsabilidade social de auxiliar na construção de propostas que norteiam o fazer da escola, sejam eles pedagógicos ou administrativos. A palavra "gestão", aqui mencionada, refere-se à gestão do processo, a uma gestão democrática e participativa. 
O diálogo-problematizador foi considerado importante, pois as escolas estavam realizando a construção do PPP e, até o momento, havia um PPP único, construído pela Secretaria Municipal de Educação (Smed). Segundo Veiga (1998, p. 1), o PPP "busca um rumo, uma direção. É uma ação intencional, com um sentido explícito, com um compromisso definido coletivamente", que se constitui como mecanismo de democratização.

O PPP é um documento importante, e sua elaboração deve ser feita em colaboração entre a direção, os professores, os funcionários, os alunos, as famílias e a comunidade, com o objetivo de traçar planos de ação e projetos para solucionar as principais dificuldades e, ainda, determinar a missão da escola. É necessário buscar a parceria das esferas administrativas superiores na execução das ações propostas pela coletividade representada. Construir o PPP de forma colaborativa e participativa é um exercício de gestão democrática, e cabe à escola pactuar os compromissos com todos os segmentos a ela relacionados. $\mathrm{O}$ diálogo que foi proposto também pode ser considerado um "momento de encontro dos sujeitos para refletir e discutir sobre um determinado objeto de conhecimento, sobre a própria realidade e os fatos que a compõem" (ABENSUR, 2009, p. 89). Por meio de uma relação horizontal, foi possível dialogar em um movimento de reflexão e criticidade.

Sendo assim, o diálogo-problematizador inicial contou com a explanação de uma professora convidada pertencente a uma Universidade Federal da região, que relatou sobre sua trajetória permanente (pessoal e profissional) com o objetivo de se aproximar das interlocutoras e produzir situações reflexivas sobre o PPP escolar. Na sequência, buscou-se conhecer o que é materializado no cotidiano educacional do município, enfatizando a importância de valorizar o campo e a cultura. No decorrer desse primeiro encontro, foi relatado pela interlocutora Esperança que as gestoras estavam em movimento de estudos, de pesquisas para impulsionar a construção de um PPP que contemplasse os anseios da comunidade escolar.

A professora convidada esclareceu que o assunto a ser problematizado não era novo, e o papel da universidade é trazer algumas questões ou relembrá-las, sempre por meio do compartilhamento de conhecimentos. Também enfatizou a importância de cada escola ter seu PPP, pois nesse documento está registrada a intenção de fazer o trabalho pedagógico, pois do contrário, “qualquer pessoa faz”. Destacou ainda que, para isso, é necessário o conhecimento da legislação educacional e das teorias que embasam o trabalho do professor. Haubert et al. 
(2022, p. 365) nos dizem que "[...] é preciso investir no pensar pedagógico, assumir uma postura crítica em relação ao fazer docente". O saber, na perspectiva do crescimento pessoal e intelectual, não pode ser apresentado de forma fragmentada, precisa considerar o entrelaçamento entre teoria e prática. Na continuidade do diálogo, a professora disse:

A familia faz o trabalho educativo, o trabalho educativo ensina, mas o pedagógico cabe a nós, professores. O projeto é político e pedagógico porque ele tem uma intenção política com a sociedade e é pedagógico porque é intencional, tem um objetivo, tem uma meta, um porquê de existir. (PROFESSORA CONVIDADA, 2019).

O PPP é um componente orientador de uma proposta pedagógica que contribua para o desenvolvimento de uma gestão democrática que represente a identidade de cada escola. A professora convidada ainda enfatizou a necessidade de compreender o PPP como um projeto que oriente a prática e seja executado, ou seja, uma proposta viva dentro da instituição, que não sirva apenas para cumprir exigências legais. Veiga (1998, p. 1) corrobora com a narrativa da professora ao dizer que: "Ao construirmos os projetos de nossas escolas, planejamos o que temos intenção de fazer, de realizar. Lançamo-nos para diante, com base no que temos, buscando o possível. É antever um futuro diferente do presente".

De acordo com o destacado no diálogo, "projeto" significa projetar para frente, referese ao que vou realizar na escola. Ainda segundo Veiga (1998, p. 1), “O projeto não é algo que é construído e em seguida arquivado ou encaminhado às autoridades educacionais como prova do cumprimento de tarefas burocráticas". O PPP registra e contém o que deve ser desenvolvido na escola. Após ser efetivamente realizado, o PPP é avaliado, e então, é hora de refazer o projeto. Nesse contexto, foi lembrado pela professora convidada que "chegou a hora de refazer o PPP ou construir porque não existe, tem que ter mudança; depois que um projeto é executado ele é reconfigurado” (PROFESSORA CONVIDADA, 2019).

Na continuidade da comunicação, a professora perguntou aos professores por que sentiam a necessidade de pensar sobre isso naquele momento. Naquele momento houve silêncio e a professora convidada retomou: "o que aconteceu de novo que é preciso modificar o projeto?". A interlocutora Esperança (2019) manifestou-se: "No nosso caso, não somente pela BNCC, temos vários motivos, vários fatores, um deles é ter um projeto por escola”. Foi evidenciado pela professora convidada que este é o caminho e que é possível fazer. 
Leão (2009) ressalta que são necessários momentos de diálogo entre os professores que favoreçam espaços de construção e formação coletiva com base na partilha e na reflexão. De acordo com Leão (2009, p. 90), "Não basta apenas apontar as fragilidades. É preciso ir além do discurso, propondo e desenvolvendo ações que realmente justifiquem a melhoria na qualidade de vida de todos os aprendizes".

Dando seguimento ao diálogo, a professora convidada problematizou a seguinte questão: "Qual é concepção que permeia o trabalho dos professores aqui no município: é competitivo ou é mais colaborativo?”. Uma das professoras da rede municipal respondeu: "essa é uma boa pergunta" (INTERLOCUTORA ALEGRIA 2019). Houve silêncio, troca de olhares e alguns sorrisos das demais professoras, e a professora convidada, após escuta sensível, seguiu o diálogo enfatizando que, se as relações na escola forem muito truncadas, difíceis, problemáticas e disputadas o tempo inteiro, não será a noção de um projeto único, que dê conta da identidade da escola que as unirá. Ressaltou, ainda, que é importante deixar as diferenças de lado e buscar união por um objetivo comum. Por fim, questionou "Como é possível reelaborar e organizar um projeto onde cada professor representa uma área sem dialogar, sem conversar com os alunos para chegar a uma reformulação curricular?”.

$\mathrm{Na}$ concepção freireana de educação, educar é uma relação interativa entre pessoas (FREIRE, 1983). O diálogo potencializa e conduz à participação, abrindo possibilidades para reflexões e aprendizagens. Na continuidade da fala, a professora convidada (2019) afirmou:

Participação é um conceito chave para se elaborar um PPP. Há duas formas de participação, estou presente, estou ali, sem qualquer contribuição pessoal minha, ou estou ali comprometida com a discussão social, uma participação ativa. Mas isso só acontece se eu me sentir à vontade. Se eu não participar, se eu não construir junto, eu não vou me sentir parte do projeto. Então, para fazer um projeto tenho que participar desde o início. Se eu não participar, eu não estou cumprindo o papel político da educação.

De acordo com o pensamento de Freire (1996), a participação resulta de um processo de aprendizagem, é prática de liberdade. Segundo o autor, "é decidindo que se aprende a decidir" (FREIRE, 1996, p. 119). O professor reflexivo apropria-se do conhecimento, criticao e emprega-o em sua prática e em suas reflexões - ação fundamental em uma concepção de 
democracia. Na sequência, as professoras trouxeram algumas das fortes características que se observam no comportamento de alguns profissionais:

Professora, sobre a questão da participação, da presença ativa, é que quando tu dás uma ideia, tu te comprometes. Ideias exigem comprometimentos, se eu não quiser me comprometer vou ficar mais na presença. É uma estratégia que a gente observa muito, por isso é que fica o projeto da dona Maria, personaliza, ela deu a ideia, é dela (INTERLOCUTORA AMOR, 2019).

Isso não é muito fácil, exige flexibilidade, por isso é necessário que às vezes a gestão se retire e fique na logística, traz o cafezinho, arruma o aparelho, porque às vezes, quem está na gestão tem muita ansiedade de fazer as coisas funcionarem. Às vezes não deixa os outros opinarem, já quer resolver, isso é uma estratégia. Também temos que ter conhecimento teórico, buscarmos os referenciais que já temos, não precisamos inventar outros. Tem que ter solidariedade, compromisso, leitura de mundo e da palavra, a mudança começa pela palavra, linguagem, nós somos feitos de palavras. Se as palavras e os conceitos forem inseguros as nossas ações também serão inseguras (PROFESSORA CONVIDADA, 2019).

Temos que estar abertos a dialogar. Há, mas tem gente que vem só para incomodar! É porque ela fala diferente, pensa diferente (PROFESSORA CONVIDADA, 2019).

Ou porque não quer nada com nada (INTERLOCUTORA LUZ, 2019).

O diálogo é uma conversa em que se fala e ouve, mas o problema das pessoas é que querem falar, mas não querem ouvir (INTERLOCUTORA ALEGRIA 2019).

Mas estas pessoas que incomodam, ou não querem nada com nada, nos colocam para pensar (PROFESSORA CONVIDADA, 2019).

Foi observado as expressões dos participantes que concordavam com o diálogo. É necessário que todos, independentemente de se expressarem de forma oral, escrita ou por meio do silêncio (que também é informativo, assim como as palavras), busquem informar-se e, constantemente, formar-se politicamente, para que tenham plena consciência dos projetos e das discussões que estão sendo desenvolvidos na escola.

De acordo com Horton e Freire (2003, p. 149), "Quanto mais as pessoas participarem do processo de sua própria educação, maior será sua participação no processo de definir o tipo de produção, e para que e por que, e maior será também sua participação no seu próprio 
desenvolvimento". O diálogo crítico e criativo é indispensável para o desenvolvimento humano, pois, a partir do respeito ao outro, é possível construir um espaço favorável para a participação, permitindo a todos a liberdade, a oportunidade e a coragem de intervir e ter voz, tendo em vista que, como proclama Freire (2009), não se democratiza sem diálogo. Quanto mais reflexivo, dialógico e democrático for o nosso agir, mais ricos e transformadores serão os resultados.

Freire (2009) trata da importância e da necessidade de criarmos condições para diálogos entre os protagonistas da escola. De acordo com o autor, o "diálogo se impõe como caminho pelo qual os homens ganham significação, enquanto homem" (FREIRE, 2009, p. 91). Vale frisar que, na perspectiva freireana, o diálogo é uma categoria central da construção do conhecimento. Defendemos o diálogo como uma troca equilibrada, na qual se ouve e fala com o outro, e não para o outro. Nessa perspectiva, o diálogo possibilita enxergar a si próprio e compreender o outro em relação a seus pensamentos e sentimentos.

No decorrer do diálogo-problematizador, também foram abordadas a caracterização e a contextualização das escolas nos seus PPPs. A coordenadora do encontro disse: "Quando o corpo docente, que está construindo o documento, se apropria de informações oriundas da comunidade, aquilo também começa a fazer parte dele e vai refletir em outros aspectos do $P P P ”$. Fatos relatados pela comunidade podem evidenciar não só as significações sociais instituídas, presentes nas histórias de vida, como também as significações instituintes (ANTUNES, 2001). Na continuidade da fala, a interlocutora Esperança (2019) relatou: “Eu não sou daqui né, mas me considero. É importante a gente pegar o documento e poder saber um pouco da história da escola, porque se perde muita coisa, as pessoas também se vão. Às vezes as pessoas mais antigas têm mais conhecimentos do que as mais novas”.

A professora convidada (2019) complementou: "Professores que estão a mais tempo, ou até aposentados conhecem mais aspectos históricos que os mais novos não conhecem, e que os novos precisam conhecer. Essa história é o ponto de partida”. Deixar emergir os sentidos que configuram a escola por meio das memórias é dar evidência às significações que dão sentido ao contexto (BATALHA, 2017). Valorizar a história de vida dos professores e da escola pode nos ajudar a entender os desafios que se apresentam na contemporaneidade.

Esses princípios norteadores têm que ser retomados teoricamente para poder entendermos o que está por trás da concepção de escola e de educação. A professora 
convidada destacou que o diagnóstico da situação atual também precisa constar no PPP, pois temos as demandas da realidade e dos alunos, que mudam a cada geração, além disso de uma hierarquia de leis e normas que precisam estar presentes nos textos do PPP: a Constituição Federal (BRASIL, 1988), lei máxima de um país, que define os princípios e as diretrizes que regem uma sociedade; as Diretrizes Curriculares Nacionais (BRASIL, 1996), que orientam o planejamento curricular das escolas e dos sistemas de ensino; a BNCC (BRASIL, 2017), que garante aos estudantes o direito de aprender conhecimentos e habilidades comuns em todo o país; e o RCG (RIO GRANDE DO SUL, 2018), documento balizador para construção dos currículos nas escolas de diferentes esferas no Estado do Rio Grande do Sul.

Além disso, contamos com orientações que são específicas para cada contexto. Para a Educação do Campo, temos as Diretrizes Operacionais para a Educação Básica das Escolas do Campo (BRASIL, 2002), que contemplam um conjunto de preocupações conceituais e estruturais presentes historicamente nas reivindicações dos movimentos sociais, e as Diretrizes Curriculares Nacionais Gerais para a Educação Básica (BRASIL, 2010), que definem a educação do campo como uma modalidade educativa e asseguram que a escola do/para o campo articule seu trabalho de acordo com sua realidade. As escolas precisam assumir e entender os programas, as ações e as decisões tomadas pelos governos (nacionais, estaduais ou municipais), pois as reflexões teórico-práticas acerca das concepções e políticas públicas possibilitam que o processo de (re)construção do PPP seja consciente e tenha consonância com a legislação nas instâncias macro e micro educacionais.

A formação permanente é um espaço importante para desenvolver uma postura crítica e especificar estas orientações. Vale destacar que as escolas com características urbanas, mas que atendem crianças oriundas de Escolas do Campo também devem atender a legislação das Escolas do Campo. Conforme Silva e Leão (2018, p. 80), "o educador necessita trazer a sua prática unida ao conhecimento adquirido juntamente com o conhecimento das políticas públicas". O conjunto de ações implementadas pelo Estado e pelas autoridades governamentais para a Educação do Campo no Brasil tem sofrido significativas reformulações nas últimas décadas. Sabemos que há necessidade de as escolas, em seus PPPs, reconhecerem as possibilidades de saberes que as legislações para esse contexto oferecem. A implementação de políticas públicas específicas para o campo, necessitam ser identificadas e analisadas. 
O espaço do campo está caracterizando-se pela heterogeneidade que apresenta, e, cada vez mais, os sujeitos que a ele pertencem estão cobrando melhorias. As propostas de ensino de uma Escola do Campo, necessariamente, precisam estar vinculadas à cultura que se produz, mediante as relações sociais que ela apresenta. Os professores da rede municipal de um município essencialmente do campo encontram-se diante de um desafio, de contemplar a diversidade do contexto e suas representações na construção dos PPPs.

O pensamento articulado e desenvolvido a partir do contexto histórico e político deve ser ampliado a partir de um diagnóstico decorrente de observação, registro, questionário, conversa com os pais, entre outros aspectos organizacionais, administrativos e financeiros. Questões que permeiam as relações interpessoais também precisam serem consideradas. Na continuidade do diálogo, a professora convidada (2019) enfatizou que "dentro do PPP tem a parte curricular, que compete a cada área, que é importante saber dos meus conhecimentos e dos outros, pois conhecer o currículo da escola facilita meu trabalho”.

Após, a professora convidada explicou que as formas de avaliação dos projetos, a duração deles e a sua avaliação devem estar definidos nos PPPs. Quando os projetos estiverem em andamento e forem realizadas mudanças, estas precisam ser modificadas nos documentos também. Outro aspecto importante que precisa estar muito claro no PPP é como a escola vai fazer a formação continuada dos professores, uma vez que é um direito previsto em lei. Além disso, a valorização profissional decorre muito dessa luta por formação, que também interfere na progressão da carreira, como bem pontuou a professora convidada (2019).

As interlocutoras da pesquisa (diretoras e supervisoras) são as articuladoras desse processo. Refletir sobre a construção, a implementação e a avaliação do PPP considerando um movimento dialógico, aponta alternativas para superar entraves na construção participativa de uma escola crítico-transformadora. Henz, Freitas e Silveira $(2018$, p. 837) afirmam que a escuta das proposições dos outros "contribui para o aprendizado mútuo e mobiliza à auto[trans]formação permanente", que é a proposta epistemológico-política dos Círculos Dialógicos Investigativo-formativos.

Para finalizar o diálogo-problematizador foi abordada a importância das Escolas do Campo do Município dialogarem entre si e criarem projetos em comum. A ideia é que os professores participem das ações desenvolvidas nas escolas, se comprometam e se sintam 
pertencentes ao lugar, de modo a acreditar no trabalho desenvolvido e valorizar as experiências e o contexto, construindo saberes e sentido à própria formação.

O PPP dá vida e materializa o currículo escolar. Sua concepção aqui defendida se constitui com base na ideia de que todos os professores são gestores, pois todos devem vivenciar de forma reflexiva com seus colegas e alunos, os objetivos e as responsabilidades do currículo escolar, defendendo a qualidade do ensino e da aprendizagem e contribuindo para o conhecimento sobre a educação. Freire (1983, p. 79) nos ensina que "Ninguém educa ninguém, como tão pouco ninguém se educa a si mesmo: os homens se educam em comunhão, mediatizados pelo mundo". De acordo com o autor, o verdadeiro sentido e significado do ato de educar objetiva superações, transformações (FREIRE, 1983). A educação fundamenta-se no diálogo, na construção e na reconstrução do ser individual, político e social. Nesse sentido, o diálogo-problematizador aqui proposto é conceituado não apenas como metodologia para a concretização da pesquisa, mas também como momento de reflexividade das interlocutoras e seu mundo.

\section{CONSIDERAÇÕES FINAIS}

Atualmente, as políticas curriculares como a BNCC, em nível nacional, e o RCG, em nível estadual, vêm impulsionando alguns municípios a fazerem suas adequações nos PPPs das escolas. Silva (2019, p. 116) ressalta que a articulação entre o conhecimento e os saberes teórico-práticos acerca das questões curriculares expressas nos PPPS das escolas "incide nas aprendizagens desenvolvidas pelos indivíduos, e, ao mesmo tempo, se inter-relacionam com os saberes ressignificados nos momentos formativos". Nesse sentido, para que possamos realmente atingir uma práxis pedagógica transformadora, devemos refletir criticamente sobre o valor e o significado da ação docente como prática social, apoiada em diversos cenários do conhecimento. O PPP é uma forma de organizar o trabalho pedagógico e está relacionado com o planejamento, a orientação e o apoio às ações escolares.

O diálogo-problematizador proposto com relação a (re)construção coletiva dos PPPs foi importante para a compreensão das orientações apresentadas nos documentos oficiais como BNCC e RCG e suas influências no processo educacional, além de ter proporcionado espaço de reflexão para entendermos que a implementação dos mesmos são oportunidades

de revisar o currículo e adotar estratégias diferenciadas. A escola como espaço de 
transformação exige posição teórico-prática e política para a compreensão de si mesma enquanto projeto educativo.

\section{REFERÊNCIAS}

ABENSUR, Patrícia Lima Dubeux. A construção curricular na perspectiva freireana: um estudo de caso na Escola Municipal Santa Rita, na cidade de Diadema - SP. 2009. 123p. Dissertação (Mestrado em Educação) - Pontifícia Universidade Católica de São Paulo, São Paulo, 2009.

ANTUNES, Helenise Sangoi. Ser aluna, ser professora: uma aproximação das significações sociais instituídas e instituístes construídas ao longo dos ciclos de vida pessoal e profissional. 2001. 266p. Tese (Doutorado em Educação) - Universidade Federal do Rio Grande do Sul, Porto Alegre, 2001.

BATALHA, Denise Valduga. Gerações e história de vida em diálogo na educação do campo, em classes multisseriadas: uma contribuição na formação de professores. 2017. 228 p. Tese (Doutorado em Educação) - Universidade Federal de Santa Maria, Santa Maria, 2017. Disponível em: https://repositorio.ufsm.br/handle/1/15687. Acesso em: 16 abr. 2019.

BRASIL. Base Nacional Comum Curricular - BNCC. Ministério da Educação. 2017 Disponível em: http://portal.mec.gov.br/conselho-nacional-de-educacao/base-nacionalcomum-curricular-bncc. Acesso em: 15 mar. 2020.

BRASIL. Constituição da República Federativa do Brasil de 1988. Diário Oficial da União, Brasília, DF, out. 1988. Disponível em:

http://www.planalto.gov.br/ccivil_03/constituicao/constituicao.htm. Acesso em: 25 nov. 2018.

BRASIL. Lei no 9.394, de 20 de dezembro de 1996. Estabelece as diretrizes e bases da educação nacional. Diário Oficial da União, Brasília, DF, 23dez.1996. Disponível em: http://www.planalto.gov.br/ccivil_03/LEIS/L9394.htm. Acesso em: 15 jul. 2015.

BRASIL. Ministério da Educação. Conselho Nacional de Educação. Câmara de Educação Básica. Resolução n ${ }^{\circ}$ 4, de 13 de julho de 2010. Define Diretrizes Curriculares Nacionais Gerais para a Educação Básica. Diário Oficial da União, Brasília, DF, 14 jul. 2010. Disponível em: https:/www.google.com/url?sa=t\&rct=j\&q=\&esrc=s\&source=web\&cd=\&ved=2ahUKEwj xi_7315DvAhVmD7kGHSDAALUQFjAAegQIARAD\&url=http\%3A\%2F\%2Fportal.mec. gov.br\%2Fdmdocuments\%2Frceb004_10.pdf\&usg=AOvVaw33xYFsNhNJtwVA9Gk1VBQ p. Acesso em: 10 dez. 2017.

BRASIL. Resolução CNE/CEB n. ${ }^{01}$. Diretrizes Operacionais para Educação Básica nas Escolas do Campo. Brasília, DF: Ministério da Educação, 2002. Disponível em: 
https://www2.camara.leg.br/legin/fed/declei/1940-1949/decreto-lei-9613-20-agosto-1946453681-publicacaooriginal-1-pe.html. Acesso em: 20 nov. 2018.

FREIRE, Paulo. Educação como prática de liberdade. São Paulo, 2011.

FREIRE, Paulo. Educação e mudança. 28. ed. São Paulo: Paz e Terra; 1979.

FREIRE, Paulo. Pedagogia da autonomia: saberes necessários à prática educativa 36. ed. São Paulo: Paz e Terra, 2009.

FREIRE, Paulo. Pedagogia da autonomia: saberes necessários à prática educativa. 13. ed. Rio de Janeiro: Paz e Terra, 1996.

FREIRE, Paulo. Pedagogia do oprimido. 13. ed. Rio de Janeiro, Paz e Terra, 1983. (Coleção O Mundo, Hoje). 21 v.

FREIRE, Paulo. Política e educação: ensaios. 5. ed. São Paulo, Cortez, 2001. (Coleção Questões de Nossa Época) 23 v.

HAUBERT, Mariel da Silva et al. Desafios Educacionais do Século XXI com Foco no Ensino Superior. Conjecturas, ISSN: 1657-5830, Vol. 22, $\mathrm{N}^{\mathrm{o}}$ 1. 2022. Disponível em https://conjecturas.org/index.php/edicoes/article/view/492/386. Acesso Jan. 2022.

HENZ, Celso Ilgo; FREITAS, Larissa Martins; SILVEIRA, Melissa Noal da. Círculos dialógicos investigativo-formativos: uma metodologia de pesquisa inspirada nos círculos de cultura freireanos. Perspectiva, Florianópolis, v. 36, n. 3, p. 835 - 850, jul./set. 2018. Disponível em: https://periodicos.ufsc.br/index.php/perspectiva/article/view/2175795X.2018v36n3p835. Acesso em: 20 dez. 2020.

HORTON, Myles; FREIRE, Paulo. O caminho se faz caminhando: conversas sobre educação e mudança social. Petrópolis: Vozes, 2003.

JOSSO, Marie-Christine. Experiência de vida e formação. Tradução de José Claúdio et al. 2. ed. rev. ampl. Natal: EDUFRN; São Paulo: Paulus, 2010.

KRAMER, S.; NUNES, M. F. Gestão pública, formação e identidade de profissionais de Educação Infantil. Cadernos de Pesquisa, v. 3, n. 131, 2007. Disponível em: https://www.scielo.br/scielo.php?script=sci_arttext\&pid=S0100-15742007000200010. Acesso em: 17 nov. 2020.

LEÃO, Débora Ortiz de. Vivências culturais nos cenários da alfabetização: formação, saberes e práticas docentes. 2009. 109 p. Tese (Doutorado em Educação) - Pontifícia Universidade Católica do Rio Grande do Sul, Porto Alegre, 2009. Disponível em: tede2.pucrs.br/tede2/bitstream/tede/3606/1/412612.pdf. Acesso em: 20 jun. 2016.

LÜCK, Heloísa. Gestão educacional: uma questão paradigmática. Petrópolis: Vozes, 2011. 
RIO GRANDE DO SUL. Resolução CEEd n 345, de 12 de dezembro de 2018.

Referencial Curricular Gaúcho. Porto Alegre, 2018. Disponível em:

https://normativasconselhos.ifal.edu.br/normativa/pdf/CEED-

RS_20181219130446resolucao0345.pdf. Acesso em: 4 jun. 2020.

SILVA, Maria Lúcia Leite da; LEÃO, Débora Ortiz de. A gestão escolar democrática e o princípio de valorização e reconhecimento do trabalho do professor. Revista de Gestão e Avaliação Educacional, Santa Maria, v. 7, n. 15, p. 77-90, maio/ago. 2018. Disponível em: https://periodicos.ufsm.br/regae/article/view/32901. Acesso em: 20 dez. 2020.

TONIOLO, J. M. dos S. de A; HENZ, Celso Ilgo. Paulo Freire no âmbito da pesquisa: os Círculos Dialógicos Investigativo-formativos como possibilidade de reinvenção dos círculos de cultura e auto(trans) formação permanente com professores. Inter-Ação, Goiânia, v. 42, n. 2, p. 519-537, maio/ago. 2017. Disponível em:

<http://dx.doi.org/10.5216/ia.v42i2.44026> . Acesso em: 17 nov. 2020.

VEIGA, Ilma Passos da. Projeto político-pedagógico da escola: uma construção coletiva. In: VEIGA, Ilma Passos da (org.). Projeto político-pedagógico da escola: uma construção possível. Campinas: Papirus, 1998. p. 11-35.

Recebido em: 03/01/2022

Aprovado em: 23/01/2022

Publicado em: 26/01/2022 